Brazilian Journal
of Chemical
Engineering

ISSN 0104-6632

Printed in Brazil

www.abeq.org.br/bjche

Vol. 26, No. 02, pp. 435 - 443, April - June, 2009

\title{
ADSORPTION OF NUCLEASE P1 ON CHITOSAN NANO-PARTICLES
}

\author{
Lu-E Shi $^{*}$ and Zhen-Xing Tang ${ }^{2}$ \\ ${ }^{1}$ College of Life and Environmental Sciences, Hangzhou Normal University, \\ Phone: 86-571-28865327, Hangzhou, 310036, Zhejiang, China. \\ ${ }^{2}$ College of Pharmaceutical Science, Zhejiang University of Technology, \\ Phone: 86-571-88320803, Hangzhou, 310032, Zhejiang, China. \\ E-mail: shilue@126.com
}

(Submitted: November 13, 2007 ; Revised: September 16, 2008 ; Accepted: January 26, 2009)

\begin{abstract}
The sorption of nuclease P1 onto chitosan nano-particles is studied in this paper. The effect of some adsorption kinetics factors such as nuclease P1 concentration, chitosan nano-particles solution concentration, adsorption temperature, chitosan nano-particles size, solution $\mathrm{pH}$, etc. is investigated. Adsorption of nuclease P1 onto chitosan nano-particles is fitted into Lagergren first-order equation at initial nuclease P1 concentration of 3.0 $\mathrm{mg} / \mathrm{mL}$. The first-order constant for nuclease P1 is $22.98 \mathrm{~h}^{-1}$. When nuclease P1 concentration is controlled into certain region, the adsorption fits into Freundlich isothermal linear equation. A mechanism of adsorption for nuclease P1 is proposed by analyzing IR spectra. The IR spectra shows that the hydrogen bond might be the main force between the hydroxyl group, the $\mathrm{NH}_{2}$ group and the nuclease $\mathrm{P}$.

Keywords: Chitosan; Nano-particles; Sorption kinetics; Sorption mechanism.
\end{abstract}

\section{INTRODUCTION}

A biopolymer, chitosan is the deacetylated form of chitin and is composed of glucosamine or (1-4)-2-amino-2-deoxy-d-glucose. Chitosan has three types of reactive functional groups, an amino group and both primary and secondary hydroxyl groups at the C-2, C-3 and C-6 positions, respectively (Fereidoon and Janak et al., 1999). This special structure allows chelation with various metal ions (Boukhlifi and Bencheikh, 2000). Muzzarelli (Muzzarelli, 1986) pointed out that chitosan combines with metal ions in three forms: ion exchange, sorption and chelation. Chitosan has been broadly used for the sorption of heavy metal ions (Coughlin and Deshaies et al., 1990; Udaybhaskar and Iyengar et al., 1990; Jansson and Guibal et al., 1996). Further physical and chemical modifications of chitosan have been made to improve the selectivity and the capacity for metals ions (Kumar and Majeti, 2000; Guibal and Jansson et al., 1995; Piron and Accominoti et al., 1997; Choong and
Wolfgang, 2003). Chitosan is also characterized by weak diffusion properties: long contact times are required to reach equilibrium. Sorption capacity can be controlled by sorbent particle size (Guibal and Jansson et al., 1995). Due to the low porosity of chitosan, sorption performances are frequently controlled by mass transfer resistance. To reduce this resistance to mass transfer, chitosan gel beads have been developed to expand the polymer structure and reduce its crystallinity (Guibal and Milot et al., 1998; Alam and Inoue et al., 1998; Hsien and Rorrer, 1997). However, these treatments resulted in either a decrease of the number of available sorption sites, or of the volumetric sorption capacity (Ruiz and Sastre et al., 2003). Controlled drying can increase the volumetric sorption capacity (Ruiz and Sastre et al., 2002). Another possibility for increasing this volumetric sorption capacity is the grafting of supplementary functional groups (Chassary and Vincent et al., 2004).

Nuclease P1 (EC 3.1.30.1), an extra-cellular enzyme was first identified by Kuninaka from

*To whom correspondence should be addressed 
Penicillium citrinum. This enzyme cleaves 5'-nucleotides successively from the 3'-hydroxy termini of $3^{\prime}$-hydroxy-terminated oligonucleotides originated from RNA. 5'-Nucleotides are known to exhibit enhancing flavor properties in food. When Nuclease P1 is added during the production of bakers yeast, the enzyme hydrolyses the yeast RNA efficiently into 5'-GMP. It has been widely used in pharmaceutical and food industry.

A number of nano-scale inorganic particles offer favorable properties for the selective removal of target contaminants. For example, hydrated Fe (III) oxides particles can selectively adsorb dissolved heavy metals like zinc, copper or metalloids like arsenic oxyacids or oxyanions (Cumbal and Greenleaf et al., 2003). Due to the small size and great surface area of nano-particles, chitosan nano-particles had been synthesized and applied as drug carriers (Xu and $\mathrm{Du}, 2003)$. However, to the best of our knowledge, few studies of nuclease P1 immobilized on chitosan nano-particles have been reported. The present work aims to study chitosan nano-particles sorption kinetics and sorption mechanism for nuclease P1.

\section{MATERIALS AND METHODS}

\section{Materials}

Chitosan was provided by Yuhuan Ocean Biochemical Co. Lit (Zhejiang, China), its molecule weight was 91,000. TPP abbreviated from Sodium polyphosphate was purchased from Dongsheng chemical reagent Factory (Zhejiang, China). All other chemicals were of analytical grade.

\section{Culture Conditions for Nuclease P1 Production}

For nuclease $\mathrm{P} 1$ production, the bacteria were grown at $30^{\circ} \mathrm{C}$ in a medium $(\mathrm{pH} 7.0)$ consisting of $(\mathrm{w} / \mathrm{v}) 3.0 \%$ sucrose, $0.10 \%$ potassium dihydrogen phosphate, $0.010 \%$ ferrous sulfate, $0.30 \%$ sodium nitrate, $0.050 \%$ magnesium sulfate, $0.050 \%$ potassium chloride, and $20 \%$ potato extract. This 24 $\mathrm{h}$ grown mother culture $(10 \mathrm{~mL})$ was used to inoculate $50 \mathrm{~mL}$ of production medium containing $(\mathrm{w} / \mathrm{v}) \quad 6.0 \%$ glucose, $0.20 \%$ peptone, $0.50 \%$ groundnut meal, $0.030 \%$ zinc sulfate, $0.040 \%$ calcium carbonate, and $0.10 \%$ potassium dihydrogen phosphate. The $\mathrm{pH}$ of the medium was adjusted to 5.4 with $\mathrm{HCl}$. Erlenmeyer flasks $(500 \mathrm{~mL})$ containing $50 \mathrm{~mL}$ of medium were incubated at $28^{\circ} \mathrm{C}$ in an orbital shaker at $240 \mathrm{rpm}$ for $49 \mathrm{~h}$. The $5 \mathrm{~N}$ phosphodiesterase solution was harvested by centrifuging at $4000 \mathrm{rpm}$ at $4{ }^{\circ} \mathrm{C}$ for $10 \mathrm{~min}$, and the supernatant thus obtained was used as the crude enzyme preparation. The enzyme was purified to homogeneity determined by sodium dodecyl sulfate polyacrylamide gel electrophoresis (SDS-PAGE) using thermal deactivation, ultrafiltration, $\left(\mathrm{NH}_{4}\right)_{2} \mathrm{SO}_{4}$ precipitation, phenyl Sepharose chromatography, ion-exchange chromatography, and gel filtration. Fig. 1 presents the results.

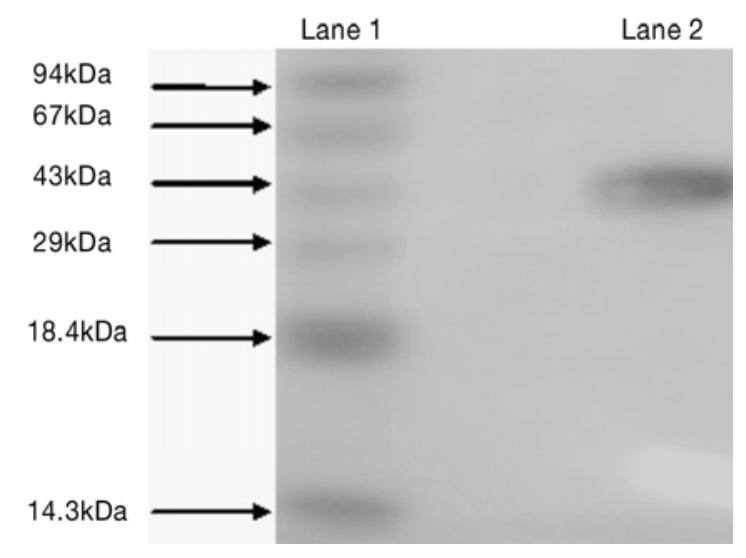

Figure 1: Electrophoretogram of protein after various steps of purification on SDSPAGE. Electrophoresis was carried out using a $15 \%$ crosslinked polyacrylamide. Lane 1: standard molecular weight markers; Lane 2: purified enzyme. 

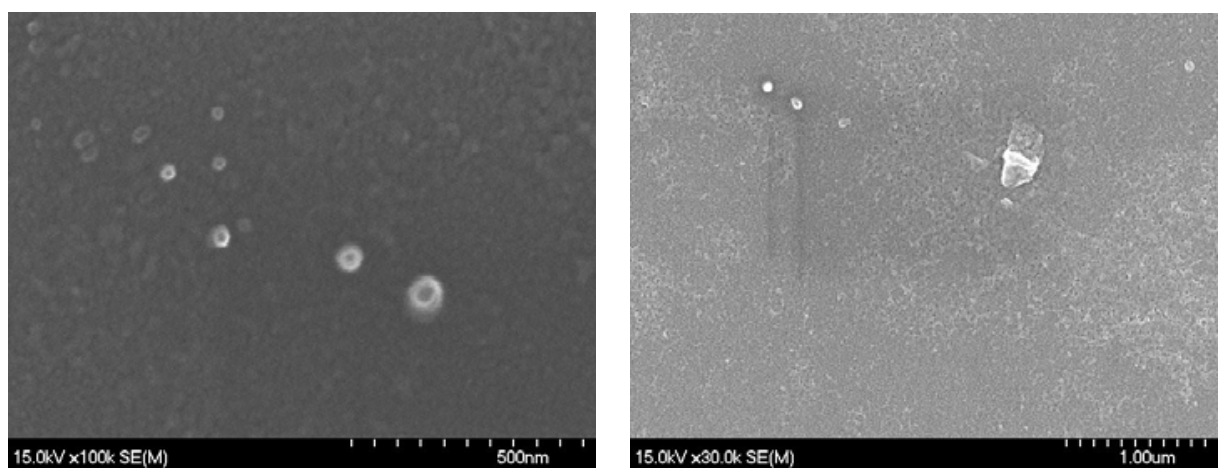

Figure 2: SEM of chitosan nano-particles. The size of chitosan nano-particles $(60 \mathrm{~nm})$ can be measured by the ruler in Figure 2.

\section{Preparation of Chitosan Nano-Particles}

$20 \mathrm{mg}$ chitosan were dissolved in $40 \mathrm{~mL}$ of $2.0 \%$ (v/v) acetic acid. $20 \mathrm{~mL}$ of $0.75 \mathrm{mg} / \mathrm{mL}$ TPP were dropped into the beaker. Then the solution was treated with super-filtration membrane to remove the residual TPP. Chitosan nano-particles were stored up in the distilled water. The morphologic characterization of chitosan nanoparticles was fulfilled by scanning electron microscope. Figure 2 presents the results.

\section{Morphology and Structure Characterization of Chitosan Nano-Particles}

Chitosan nano-particles were gold coated using a Hitachi coating unit IB-2 coater under a high vacuum, 0.1 Torr, high voltage, $1.2 \mathrm{kV}$ and $50 \mathrm{~mA}$. Coated samples were examined using a XL30-SEM scanning electron microscope to characterize the morphology and size of nano-particles.

FT-IR of chitosan nano-particles were taken with $\mathrm{KBr}$ pellets on Nicolet Nexus 670 Spectrum FT-IR. The samples were chitosan, chitosan nano-particles, chitosan nano-particles with adsorbed nuclease P1 respectively.

\section{Sorption Kinetics Experiments}

Batch experiments for determination of kinetics of nuclease P1 on chitosan nano-particles were carried out using a continuously stirred glass vessel. Different concentrations of different mean particle sizes chitosan nano-particles solutions were brought in contact with $1.0 \mathrm{~mL}$ nuclease $\mathrm{P} 1$ solutions under continuous stirring, at temperature $\left(30 \sim 60^{\circ} \mathrm{C}\right)$. The $\mathrm{pH}$ was 7.0. The initial concentration of nuclease P1 was varied to investigate its effect on the sorption kinetics. During the kinetic experiments, samples were withdrawn at fixed time intervals, filtered, and analyzed with an UV/visible spectrometer 751 (Shanghai, China).

\section{Equilibrium Experiments}

Batch equilibrium experiments were carried out using chitosan nano-particles as sorbent. A series of flasks containing nuclease P1 solutions of varied concentrations prepared from nuclease $\mathrm{P} 1$ and a fixed concentration of chitosan nano-particles were agitated in a rotary shaker at room temperature. Nuclease P1 uptake experiments were conducted under $\mathrm{pH}$ 7.0. After reaching equilibrium, nuclease P1 solutions were filtered and analyzed. Nuclease P1-free and sorbent-free blanks were used as controls. Amounts of nuclease P1 taken up by the sorbent in each flask were determined by the following mass balance equation:

$\mathrm{Q}=\frac{\mathrm{V}\left(\mathrm{C}_{0}-\mathrm{C}_{\mathrm{e}}\right)}{\mathrm{W}}$

where $\mathrm{Q}$ is the sorption capacity $(\mathrm{mg} / \mathrm{g}), \mathrm{C}_{0}$ and $\mathrm{C}_{\mathrm{e}}$ are, respectively, the initial and solution phase nuclease $\mathrm{P} 1$ concentration at equilibrium $(\mathrm{mg} / \mathrm{L}), \mathrm{V}$ the solution volume (L), and $\mathrm{W}$ the mass of sorbent $(\mathrm{g})$.

\section{RESULTS AND DISCUSSION}

\section{Characterization of Chitosan Nano-Particles}

\section{a) Size and Morphology of Chitosan Nano-Particles}

The preparation of chitosan nano-particles was based on an ionic gelation interaction between 
positively-charged chitosan and negatively-charged tri-polyphosphate (Kevin and Marie et al., 2001; Angela and Alejandro, 2001). Chitosan nano-particles prepared in the experiment exhibited white powder shape. Results are shown in Figure 2.

\section{b) Surface Functional Groups of Chitosan Nano-Particles}

Spherical chitosan tri-polyphosphate chelating beads have been prepared and applied in the field of metal ions adsorption due to the enhanced intra-particular diffusion and excellent uptake capacity (Lee and Mi et al., 2001). In this work, in order to increase the sorption capacity of chitosan, chitosan nano-particles were prepared by ionic gelation of chitosan and tri-polyphosphate.

FT-IR spectra of chitosan and chitosan nano-particles were analyzed, and results showed that the $\mathrm{CONH}_{2}$ and $\mathrm{NH}_{2}$ groups of chitosan are both slightly cross-linked with a sodium polyphosphate molecule (Figures 3 and 4) (Qi and Xu et al., 2004). Nuclease $\mathrm{P} 1$ adsorbed nano-particles were formed by sorption of nuclease P1. As can be seen from the IR spectrum of chitosan nano-particles, the peak indicating $\mathrm{P}=\mathrm{O}$ stretching at $1217 \mathrm{~cm}^{-1}$ appears (Lee and $\mathrm{Mi}$ et al., 2001), but disappears for the nano-particles after adsorbing nuclease $\mathrm{P} 1$ due to the hydrogen bond between nuclease $\mathrm{P} 1$ and phosphoric groups. The peaks at $1066 \mathrm{~cm}^{-1}(\mathrm{OH})$ in the spectrum of nuclease P1 adsorbed nano-particles are sharper in Figure 5. This behavior reflects the interaction between the amino groups and nuclease P1. Therefore, chitosan nano-particles provided sorption sites for nuclease P1 except the amino and hydroxyl groups.

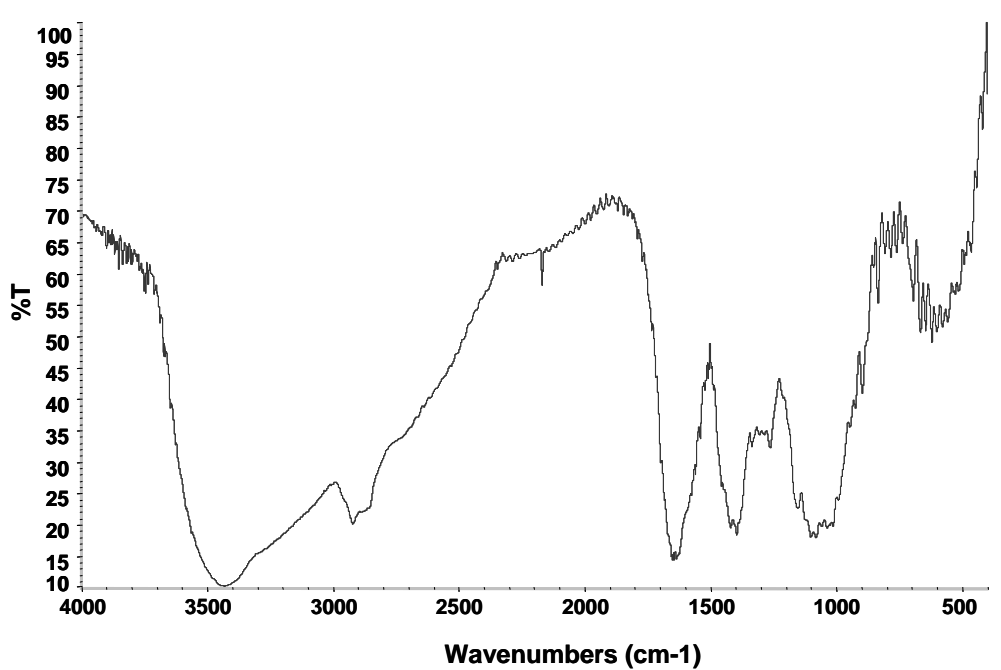

Figure 3: Infrared spectra of chitosan

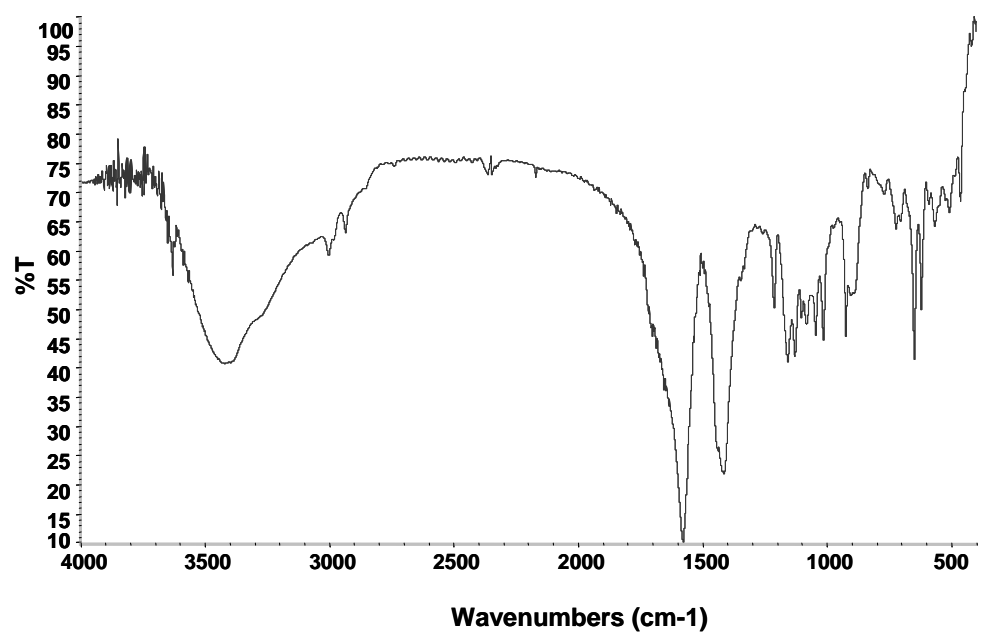

Figure 4: Infrared spectra of chitosan nano-particles 


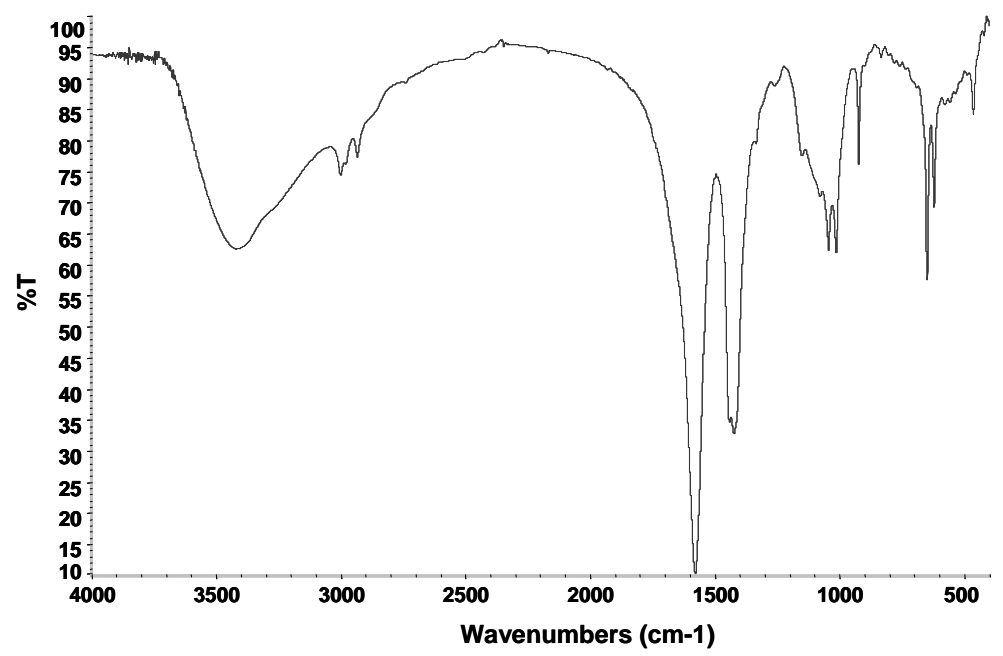

Figure 5: Infrared spectra of chitosan nano-particles with adsorbed nuclease P1

\section{Sorption Kinetics for Nuclease P1}

\section{a) Influence of Nuclease P1 Concentration}

The effect of different initial concentration of nuclease P1 solution on the sorption kinetics is illustrated in Figure 6. The higher the initial concentration of nuclease $\mathrm{P} 1$, the greater time it takes to reach equilibrium and the lower the sorption rate that is obtained. Nuclease P1 was adsorbed fast, more than $60 \%$ in $10 \mathrm{~min}$. When the initial concentration of nuclease P1 was $1.0 \mathrm{mg} / \mathrm{mL}$, the sorption rate reached $80.0 \%$ at $10 \mathrm{~min}$. And the equilibrium time was $24.5 \mathrm{~min}$. When the initial concentration of nuclease P1 was increased to 5.0 $\mathrm{mg} / \mathrm{mL}$, the sorption rate was $79.0 \%$ at $10 \mathrm{~min}$. The sorption reached equilibrium after $30 \mathrm{~min}$. And the sorption rate increased to $97.5 \%$. Chitosan nano-particles could adsorb nuclease P1 quickly, and exhibited a high sorption capacity.

\section{b) Influence of Nano-Particles Concentration}

When the number of nano-particles was increased the amount of nuclease P1 adsorbed by chitosan nano-particles also increased. Figure 7 shows the results obtained for chitosan nano-particles in contact with nuclease P1 solution.

\section{c) Influence of Temperature}

Figure 8 shows the sorption kinetics obtained at different temperatures with chitosan nano-particles. The residual nuclease P1 concentration slightly increased when temperature was increased from 25 to $45^{\circ} \mathrm{C}$. The sorption rate began to decrease at $45^{\circ} \mathrm{C}$. This phenomenon might be explained if chitosan nano-particles were assembled at high temperatures. Previous studies have shown little differences for usual temperatures (in the range $5-55^{\circ} \mathrm{C}$ ) for copper, zinc or mercury sorption (McKay and Blair et al., 1989).

\section{d) Influence of Mean Size}

Figure 9 shows a higher sorption capacity when the mean size of chitosan nano-particles decreases. Chitosan nano-particles with mean size $60 \mathrm{~nm}$ had a high sorption capacity when they were contacted with nuclease P1 solution. Increasing the size of the nano-particles, increased the time required to reach equilibrium. The contact surface of little size nano-particles could explain the differences for nuclease P1 sorption among various mean sizes of nano-particles. The sorption performance of chitosan can be affected significantly by the particle size and the conditioning of the absorbent due to the diffusion restrictions caused by the low porosity and crystallinity of the raw chitosan (Guibal and Jansson et al., 1995).

\section{e) Influence of Agitation Speed}

Figure 10 shows that the sorption rate of nuclease P1 was increased significantly with the increase of the agitation speed in a short contact time, while the sorption rate showed little difference at equilibrium. Therefore, nuclease P1 sorption rate was independent of the agitation speed. Similar results for cadmium sorption on chitosan were obtained by Dzul et al., (Dzul and Saucedo et al., 2001). 


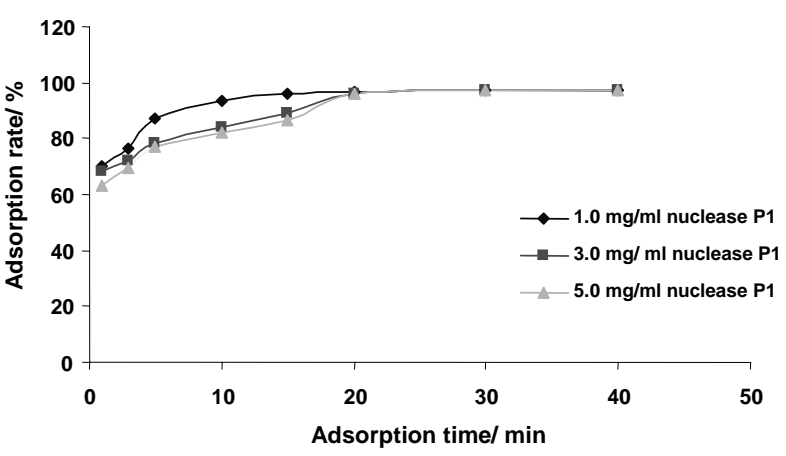

Figure 6: Effect of nuclease P1 concentration on adsorption

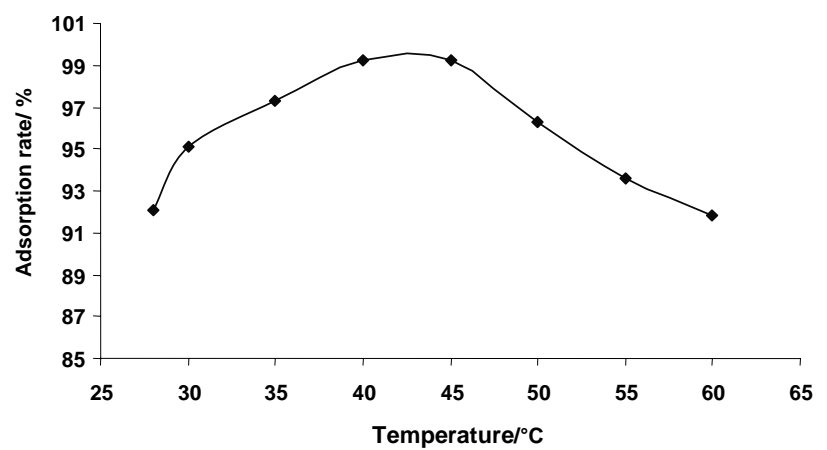

Figure 8: Effect of temperature on adsorption

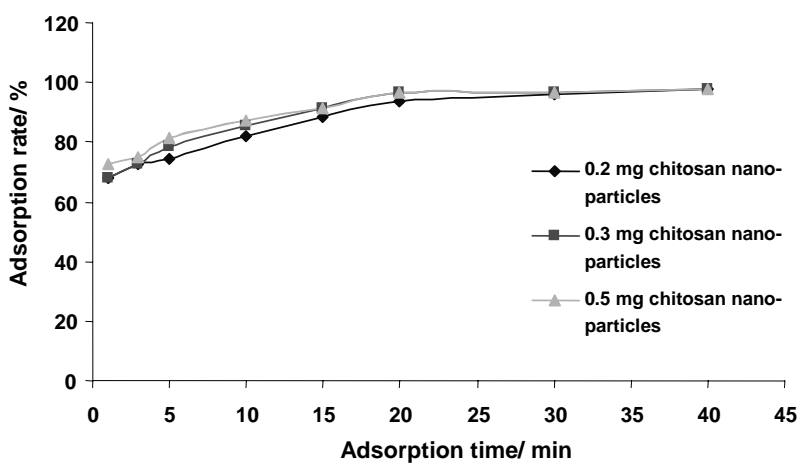

Figure 7: Effect of nano-particles concentration on adsorption

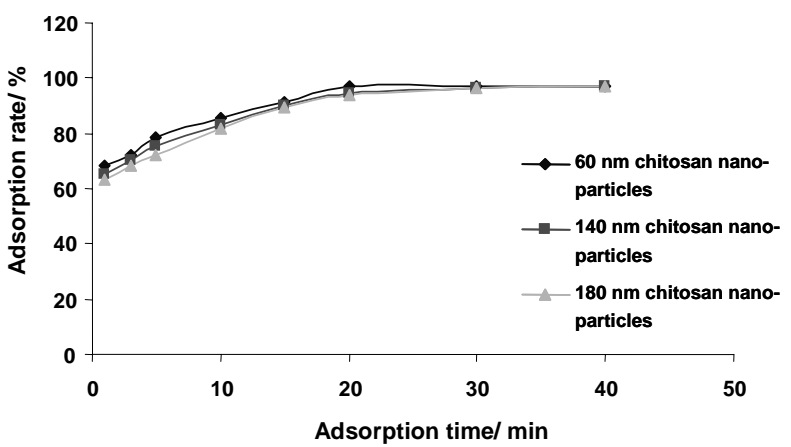

Figure 9: Effect of size of nano-particles on adsorption

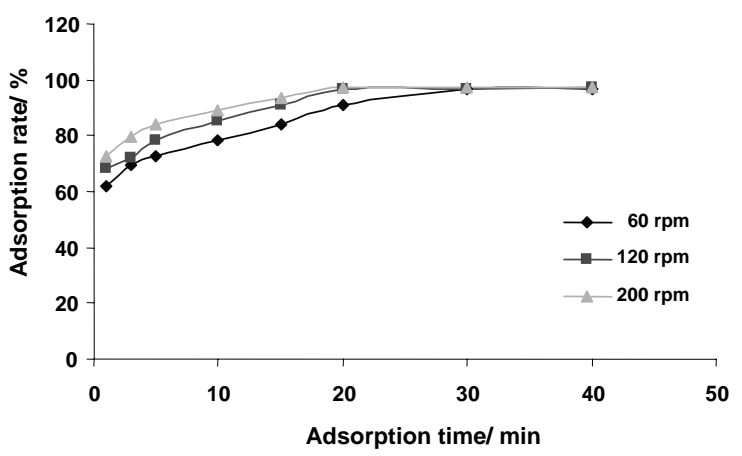

Figure 10: Effect of agitation speed on adsorption

\section{Influence of pH Value on Sorption}

Figure 11 shows the effect of $\mathrm{pH}$ on the sorption of nuclease P1 by chitosan nano-particles. It was found that the sorption efficiency increased when the $\mathrm{pH}$ of the solution was increased from 6.0 to 7.3. At low $\mathrm{pH}$ values of the solution, the amine and tri-poly-phosphoric groups were protonated to varied degrees, reducing the number of binding sites available for nuclease P1 uptake so that the extent of nuclease P1 uptake was low at high concentrations of protons. Moreover, the protonation of amine and phosphoric groups induced an electrostatic repulsion of nuclease P1 cations. When the $\mathrm{pH}$ of the solution was higher than 7.3, chitosan nano-particles began to resemble. So the sorption rate began to decrease. Similar results were shown using chitosan gel beads to study the influence of $\mathrm{pH}$ on metal sorption (Dzul and Saucedo et al., 2001).

\section{Sorption Isotherms}

Figure 12 shows the experimental equilibrium isotherms for sorption of nuclease P1 on chitosan nano-particles. Nuclease P1 was absorbed very quickly within $24 \mathrm{~min}$. After $24 \mathrm{~min}$, the adsorption reached equilibrium.

The first-order rate expression of Lagergren is 
given as:

$$
\log \left(q_{e}-q\right)=\log \left(q_{e}\right)-k_{1} t / 2.3
$$

where $\mathrm{q}_{\mathrm{e}}$ and $\mathrm{q}$ are the amounts of nuclease $\mathrm{P} 1$ adsorbed on chitosan nano-particles at equilibrium and at time $\mathrm{t}$, respectively, and $\mathrm{k}_{1}$ is the rate constant of first-order adsorption. The slope and intercepts of the plots of $\log \left(q_{e}-q\right)$ Vs t were used to determine the first-order rate constant $\mathrm{k}_{1}$. The adsorption of nuclease P1 was fit to first-order of Lagergren, $\mathrm{k}_{1}$ was calculated as $22.98 \mathrm{~h}^{-1}$.

The most important model of monolayer adsorption came from the work of Langmuir (Langmuir, 1918). Their sorption behaviors could be described with the Langmuir adsorption equation (Bayramoglu and Denizli et al., 2002) as:

$$
\frac{\mathrm{C}_{\mathrm{e}}}{\mathrm{Q}}=\frac{\mathrm{C}_{\mathrm{e}}}{\mathrm{Q}_{\max }}+\frac{1}{\mathrm{Q}_{\max }} \mathrm{b}
$$

where $\mathrm{Ce}$ is the equilibrium concentration of nuclease P1 (mg/L), Q the amount of nuclease P1 adsorbed per unit weight of chitosan nano-particles at equilibrium $(\mathrm{mg} / \mathrm{mg}), \mathrm{Q}_{\max }$ the maximum sorption at monolayer coverage $(\mathrm{mg} / \mathrm{mg})$ and $\mathrm{b}$ is the

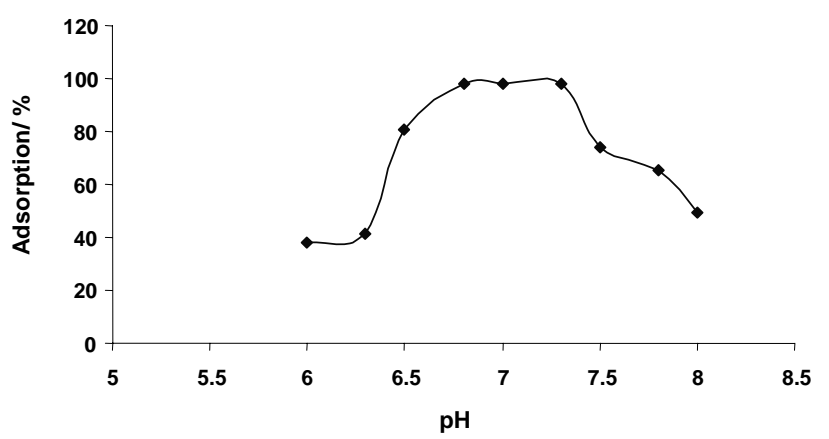

Figure 11: Effect of $\mathrm{pH}$ on adsorption

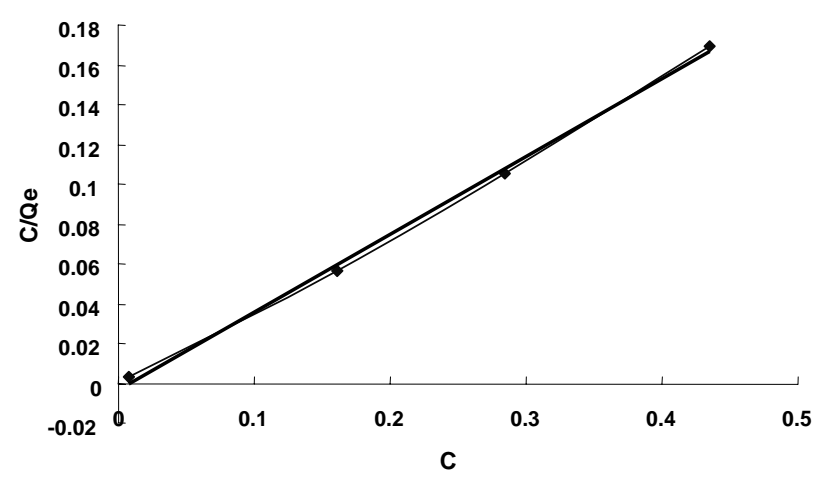

Figure 13: Langmuir adsortion isotherm
Langmuir sorption equilibrium constant $(\mathrm{mL} / \mathrm{mg})$ and it is a measure of the energy of sorption.

A linearized plot of $C_{e} / Q$ versus $C_{e}$ (Figure 13) gave $\mathrm{Q}_{\max }$ and $\mathrm{b}$, the results obtained were: $\mathrm{Q}_{\max }=$ $2.56 \mathrm{mg} / \mathrm{mg}$ and $\mathrm{b}=0.0016(\mathrm{~mL} / \mathrm{mg})$. The equation is $\mathrm{C}_{\mathrm{e}} / \mathrm{Q}=0.3913 \mathrm{C}_{\mathrm{e}}+0.0038$. The plots demonstrated that the Langmuir equation provided a reasonable description of the experimental data.

The other well-known isotherm used to describe adsorption behavior was the Freundlich isotherm (Figure 14). The isotherm was another form of the Langmuir approach for adsorption on a heterogeneous surface. The amount of adsorbed material was the sum of adsorption on all sites. The Freundlich isotherm described reversible adsorption and was not restricted to the formation of the monolayer. This empirical equation took the form:

$$
\mathrm{C}=\mathrm{K}_{\mathrm{F}}\left(\mathrm{Q}_{\mathrm{e}}\right)^{1 / \mathrm{n}}
$$

where $\mathrm{K}_{\mathrm{F}}$ and $\mathrm{n}$ are the Freundlich constants characteristics of the system, $\mathrm{K}_{\mathrm{F}}$ and $\mathrm{n}$ are indicators of the adsorption capacity and adsorption intensity, respectively. The slope and the intercept of the linear Freundlich equation are equal to $1 / \mathrm{n}$ and $\log \mathrm{K}_{\mathrm{F}}$, respectively. In this experiment, $\mathrm{n}$ was 0.10 , the adsorption intensity to nuclease P1 was weak.

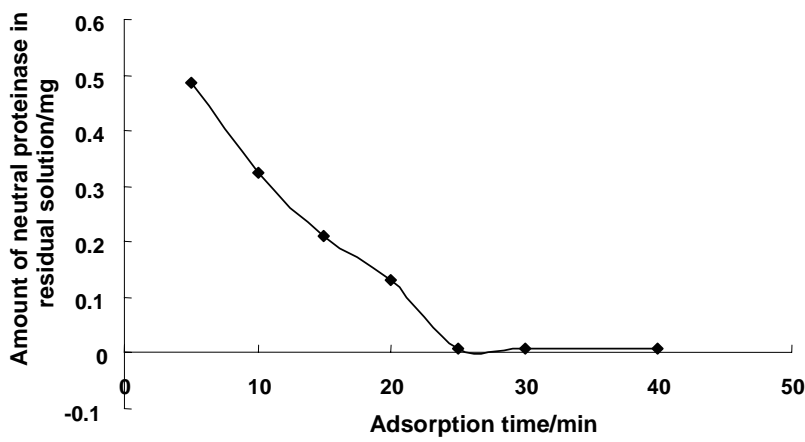

Figure 12: Adsorption isotherm Adsorption temperature: $30^{\circ} \mathrm{C}$; Agitation speed: $120 \mathrm{rpm}$;

Bulk concentration: $3.0 \mathrm{mg} / \mathrm{ml}$

logQe

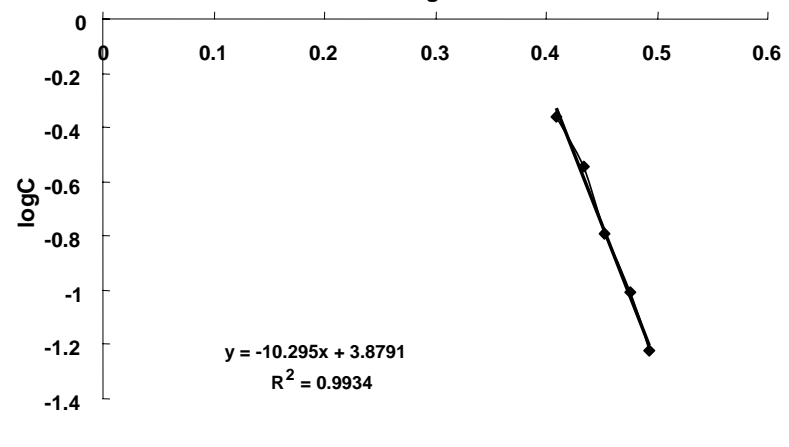

Figure 14: Freundlich adsorption isotherm 

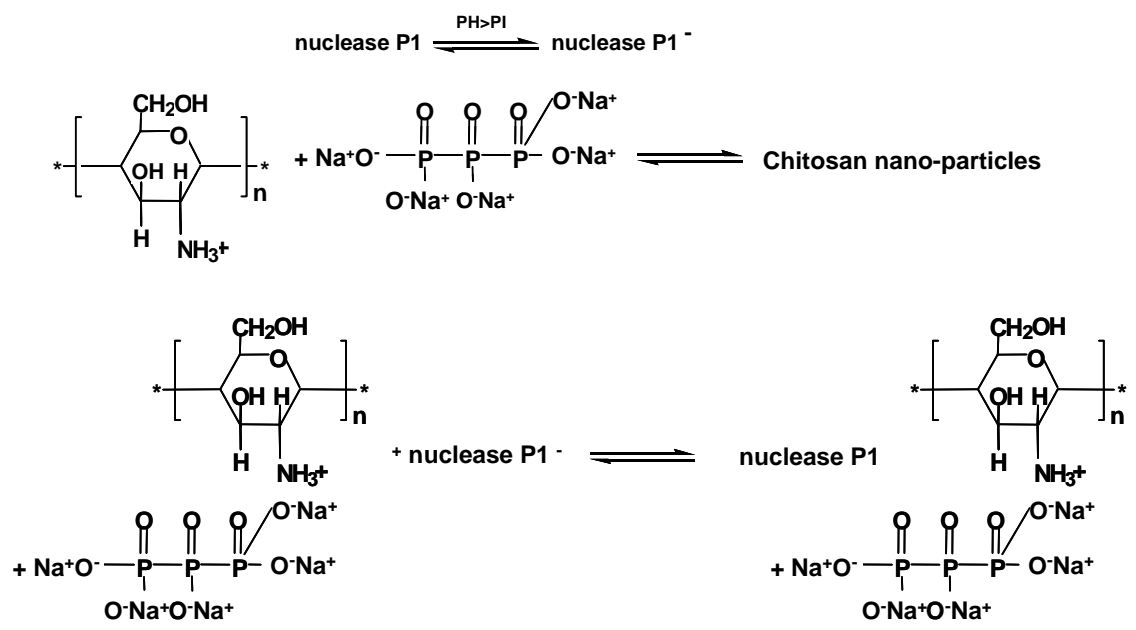

Figure 15: Hypothesis of adsorption mechanism

\section{Hypothesis of Adsorption Mechanism}

Nuclease P1 was a cation when the initial solution $\mathrm{pH}$ was 7.0, chitosan nano-particles were anions (Figure 15).

The $\mathrm{n}$ is less than 0.5 in the Freundlich equation. We can observe it was very easy to adsorb nuclease P1 with chitosan nano-particles. The interactivity strength between $\mathrm{NH}_{2}$ group, hydroxyl group and nuclease P1 was hydrogen bond force.

The hydrogen in the carboxyl group was connected with electronegative oxygen. Electron pair was attractive to oxygen, so the hydrogen atom became cation and proton. When electronegative nuclease P1 was close to chitosan nano-particles, the hydrogen bond might be formed (Figure 15). It was the main force between hydroxyl group, $\mathrm{NH}_{2}$ group and nuclease P1.

\section{CONCLUSION}

Chitosan nano-particles were prepared by ionic gelation of chitosan and tri-polyphosphate. The results of the experiments showed that chitosan nano-particles could adsorb nuclease P1 from aqueous solution effectively. The experimental data of the sorption equilibrium from nuclease P1 solution correlated well with the Langmuir isotherm equation. The high sorption capacity of chitosan nano-particles for nuclease $\mathrm{P} 1$ indicated a promising adsorbent. FT-IR spectra revealed the functional groups of chitosan nano-particles and the interaction with nuclease $\mathrm{P} 1$, the amine and hydroxyl group of nano-particles provided sorption sites for nuclease $\mathrm{P} 1$.

\section{REFERENCES}

Alam, M. S., Inoue, K., Yoshizuka, K., Ishibashi, H., Adsorptive Separation of Rhodium(11l) Using Fe(Ill)- Templated Oxine Type of Chemically Modified Chitosan, Separation Science and Technology, 33, No. 5, 655 (1998).

Angela, M. D. C., Alejandro, S. M. and Alonso, J., Chitosan nanoparticles: a new vehicle for the improvement of the delivery of drugs to the ocular surface, Application to cyclosporin A, International Journal of Pharmaceutics, 224, No. $1-2,159$ (2001).

Bayramoglu, G., Denizli, A., Bekatas, S. and Arica, M. Y., Entrapment of Lentinus sajor-caju into Ca-alginate gel beads for removal of Cd(II) ions from aqueous solution: preparation and biosorption kinetics analysis, Microchemical Journal, 72, No.1 , 63 (2002) .

Boukhlifi, F., Bencheikh, A., Characterization of natural biosorbents used for the depollution of waste water, Annales de Chimie Science des Materiaux, 25, No.2, 153 (2000).

Chassary, P., Vincent, T. and Guibal, E., Metal anion sorption on chitosan and derivative materials: a strategy for polymer modification and optimum use, Reactive and Functional Polymers, 60, Special Issue, 137 (2004).

Choong, J. and Wolfgang, H. H., Chemical modification of chitosan and equilibrium study 
for mercury ion removal, Water Research, 37, No. 19, 4770 (2003).

Coughlin, R. W., Deshaies, M. R. and Davis, E. M., Chitosan in crab shell wastes purifies electroplating wastewater, Environmental Progress, 9, No.1, 35 (1990).

Cumbal, L., Greenleaf, J., Leun, D. and Sengupta, A. K., Polymer supported inorganic nanoparticles: characterization and environmental applications, Reactive and Functional Polymers, 54, No. 1-3, 167 (2003).

Dzul, E. M. S., Saucedo M. T. I., Mendoza, R. N., Rodriguez, M. A., and Guibal, E., Cadmium sorption on chitosan sorbents: kinetic and equilibrium studies, Hydrometallurgy, 61, No.3, 157 (2001).

Fereidoon, S, Janak, K. V. A. and Jeon Y. J., Food applications of chitin and chitosans, Trends in Food Science \& Technology, 10, No. 2, 37 (1999).

Guibal, E., Jansson C. M., Saucedo, I. and Cloirec, P. L., Enhancement of Metal Ion Sorption Performances of Chitosan: Effect of the Structure on the Diffusion Properties, Langmuir 11, No.2, 591 (1995).

Guibal, E., Milot, C. and Tobin, J. M., Metal-Anion Sorption by Chitosan Beads: Equilibrium and Kinetic Studies, Industrial \& Engineering Chemistry Research, 37, No.4, 1454 (1998).

Hsien, T. Y. and Rorrer, G. L., Heterogeneous Cross-Linking of Chitosan Gel Beads: Kinetics, Modeling, and Influence on Cadmium Ion Adsorption Capacity, Industrial \& Engineering Chemistry Research, 36, No.9, 3631 (1997).

Jansson C. M., Guibal, E., Roussy, J., Delanghe, B. and Cloirec, P., Vanadium (IV) sorption by chitosan: Kinetics and equilibrium, Water Research, 30, No.2, 465 (1996).

Kevin, A. J., Marie, P. F., Ana, M., Angels, F. and Maria, J. A., Chitosan nanoparticles as delivery systems for doxorubicin, Journal of Controlled Release, 73, No. 2-3, 255 (2001).

Kumar, R. and Majeti, N. V., A review of chitin and chitosan applications, Reactive and Functional Polymers, 46, No. 1, 1 (2000).

Langmuir, I., The adsorption of gases on plane surfaces of glass, mica and platinum, Journal of the American Chemical Society, 40, No. 9, 361 (1918).

Lee, S. T., Mi, F. L., Shen, Y. J. and Shyu, S. S., Equilibrium and kinetic studies of copper(II) ion uptake by chitosan-tripolyphosphate chelating resin, Polymer, 42, No.5, 1879 (2001).

McKay, G., Blair, H. S. and Findon, A., Equilibrium studies for the sorption of metal ions onto chitosan, Indian Journal of Chemistry, 28A, No. 2, 356 (1989).

Muzzarelli, R. A. A., Chitin, Pergamon Press, Oxford (1986).

Piron, E., Accominoti, M. and Domard, A., Interaction between Chitosan and Uranyl Ions, Role of Physical and Physicochemical Parameters on the Kinetics of Sorption, Langmuir 13, No. 6, 1653 (1997).

Qi, L. F, Xu, Z. R., Jiang, X., Hu, C. H. and Zou, X. F., Preparation and antibacterial activity of chitosan nanoparticles, Carbohydrate Research, 339 , No. 16, 2693 (2004).

Ruiz, M. A., Sastre, A. M. and Guibal, E., Extraction of Lanthanides with Mixtures of Crown Ethers and Heptanoic Acid, Solvent Extraction and Ion Exchange, 21, No. 5, 736 (2003).

Ruiz, M. A., Sastre, A. M. and Guibal, E., Pd and Pt recovery using chitosan gel beads. I. Influence of the drying process on diffusion properties, Separation Science and Technology, 37, No. 9, 2143 (2002).

Udaybhaskar, P., Iyengar, L. and Prabhakara, A. V. S., Hexavalent chromium interaction with chitosan, Journal of Applied Polymer Science, 39, No.3, 739 (1990).

Xu. Y. M. and Du. Y. M., Effect of molecular structure of chitosan on protein delivery properties of chitosan nanoparticles, International Journal of Pharmaceutics, 250, No.1, 215 (2003). 